\title{
Forest fire danger rating in complex topography - results from a case study in the Bavarian Alps in autumn 2011
}

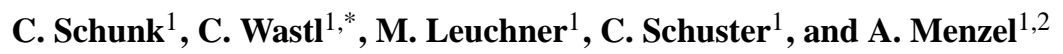 \\ ${ }^{1}$ Chair of Ecoclimatology, Technische Universität München, Hans-Carl-von-Carlowitz-Platz 2, 85354 Freising, Germany \\ ${ }^{2}$ Institute for Advanced Study, Technische Universität München, Lichtenbergstr. 2a, 85748 Garching, Germany \\ * now at: Central Institute for Meteorology and Geodynamics, Vienna, Austria
}

Correspondence to: C. Schunk (schunk@wzw.tum.de)

Received: 27 February 2013 - Published in Nat. Hazards Earth Syst. Sci. Discuss.: 19 April 2013

Revised: 13 July 2013 - Accepted: 31 July 2013 - Published: 6 September 2013

\begin{abstract}
Forest fire danger rating based on sparse meteorological stations is known to be potentially misleading when assigned to larger areas of complex topography. This case study examines several fire danger indices based on data from two meteorological stations at different elevations during a major drought period.

This drought was caused by a persistent high pressure system, inducing a pronounced temperature inversion and its associated thermal belt with much warmer, dryer conditions in intermediate elevations. Thus, a massive drying of fuels, leading to higher fire danger levels, and multiple fire occurrences at mid-slope positions were contrasted by moderate fire danger especially in the valleys. The ability of fire danger indices to resolve this situation was studied based on a comparison with the actual fire danger as determined from expert observations, fire occurrences and fuel moisture measurements.

The results revealed that, during temperature inversion, differences in daily cycles of meteorological parameters influence fire danger and that these are not resolved by standard meteorological stations and fire danger indices (calculated on a once-a-day basis). Additional stations in higher locations or high-resolution meteorological models combined with fire danger indices accepting at least hourly input data may allow reasonable fire danger calculations under these circumstances.
\end{abstract}

\section{Introduction}

\subsection{Forest fire danger rating fundamentals and purposes}

Forest fires are an important natural hazard influencing public safety, ecology and management as well as productivity of forests in many countries around the world. In order to facilitate fire danger assessment on a given day and location, fire danger rating systems have been developed which integrate meteorological variables (and potentially additional factors) to produce numeric indices of fire potential (Chandler et al., 1983; Davis, 1959; Pyne et al., 1996). In addition to indices covering this original definition of fire danger (e.g. McArthur's Forest Fire Danger Index), others relating to more specific aspects of fire danger - such as fuel moisture, which can be used to estimate the probability of ignition (Van Wagner, 1987) - are also available. Depending on local environmental conditions and the desired application, all of these can be used as a management tool e.g. for preparedness planning, public information and warnings, mutual assistance and scheduling of prescribed fires (Baumgartner et al., 1967; Camia et al., 2006; Pyne et al., 1996). Therefore, all indices used in this paper will be referred to as "fire danger indices".

\subsection{Effects of mountain meteorological phenomena on forest fires and fire danger rating}

The diverse effects of mountain meteorological phenomena on forest fire danger and behaviour have been described by several authors (e.g. Butler et al., 1998; Gorski and 
Farnsworth, 2000; Holden and Jolly, 2011; Millán et al., 1998; Miller and Schlegel, 2006; Ryan, 1969). A comprehensive overview can be found in Sharples (2009). Key phenomena include changes of temperature and relative humidity associated with exposition and elevation, leading to a distinctive spatial distribution of fuel types, effects on snowmelt and fuel moisture patterns, as well as diurnal mountain wind systems (e.g. thermally-caused along-slope, alongvalley, cross-valley and mountain-plain wind systems, all affecting fire behaviour and especially the direction of fire spread). More complex features comprise temperature inversions and associated thermal belt formation (conditions more favourable to wildfires at mid-slope than at lower and higher elevations, McRae and Sharples, 2011) and thermodynamic foehn winds (warm and dry katabatic lee slope winds causing high fire danger and intensive fire behaviour). Further mountain wind effects are dynamic channelling (a combination of upper winds and complex topography potentially leading to unexpected extreme fire behaviour and spotting), low-level jets (narrow currents of fast moving air influencing fire behaviour), and deflections and perturbations of airflows by mountainous terrain (mountain wind waves (e.g. gravity waves) linked to induced instability, strong gusty winds potentially leading to blow-ups, and thunderstorms with lightning as an ignition source) (Sharples, 2009, and the references therein).

Holden and Jolly (2011) modelled topographic influences on fuel moisture and fire danger from a network of temperature and relative humidity sensors, digital elevation models and one meteorological station. Their results show a high heterogeneity of fuel moisture and fire danger in the study area. In addition to aspect, cold air drainage with subsequent temperature inversion and thermal belt formation were found to be a major cause of this heterogeneity.

\subsection{The general situation in the Bavarian Alps}

Forest fire danger along the northern rim of the European Alps and in particular in southern Germany is usually quite moderate due to the temperate climate of the prevailing westerlies with relatively frequent year-round precipitation. Both large-scale (orographically enhanced) and convective precipitation are the most important reasons for this (cf. Fig. 1); the summer maximum of precipitation is caused by convection, which markedly decreases the forest fire danger when temperatures are highest. However, there are occasional dry spells, during which fire danger can rise significantly. A considerable fire hazard can result when such periods occur in spring, when the dead ground fuels (grass) remaining from the previous year dry most rapidly.

Overall, these conditions lead to an average of 36 forest fires per year, affecting an area of 19.8 ha (reference period 2005-2011) in the whole state of Bavaria (total area $70,552 \mathrm{~km}^{3}$, of which $35 \%$ is forested). Most of these (few and small) fires occur in the lowlands, with, on average, only

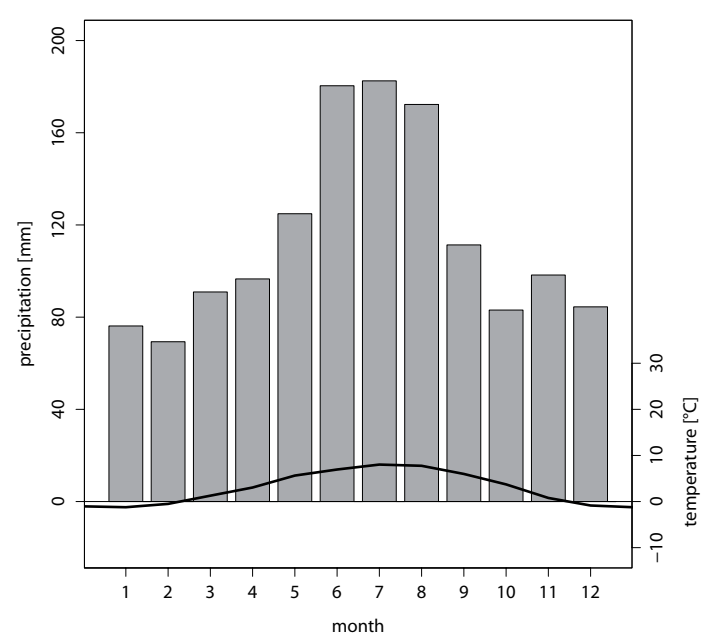

Fig. 1. Climograph for the meteorological station GarmischPartenkirchen $\left(719 \mathrm{~m}\right.$ a.s.1., $\left.47.48^{\circ} \mathrm{N}, 11.06^{\circ} \mathrm{E}\right)$; black line: mean monthly temperature, grey bars: mean monthly precipitation sums, reference period: 1971-2000.

two fires per year ( 8.8 ha burnt area per year) taking place in the Alpine area itself.

However, vulnerability to forest fires is much higher in the Alpine area than in the plains, because the steepness of the terrain as well as the relative openness of forests near the timber line cause much faster drying of fuels, more severe fire behaviour and more difficult fire-fighting operations (also reflected in the larger average burnt area per fire). Additionally, most Alpine forests have important protective functions, e.g. against avalanches, rock fall and debris flows, and a loss or disturbance of those forests is especially worrying. Last but not least, forest restoration in this terrain is definitely more difficult and expensive than in other areas.

\subsection{Autumn 2011 weather conditions}

In autumn 2011, a meteorological situation occurred which resulted in elevated fire danger at the northern rim of the European Alps at a time when the first snows would normally have been expected. During this time, hardly any precipitation occurred due to persistent high pressure systems over Central Europe for more than one month. Mean precipitation recorded for the whole of Germany (approx. $3 \mathrm{~mm}$ ) indicates that November 2011 was the driest month since the start of systematic meteorological observations in 1881 (DWD, 2011a). At many meteorological stations, no precipitation at all was registered. In contrast to the lowlands, where this drought event was accompanied mostly by foggy and cold weather, clear skies and high temperatures prevailed at higher elevations (DWD, 2011a; Zimmermann and Raspe, 2012; Raspe et al., 2012). This was due to strong subsidence in the high pressure systems causing very stable conditions 
with a distinctive temperature inversion during the nights and early mornings.

The fire danger was further increased by dry-warm katabatic foehn winds from the south of the Alps on several days. In addition, some annual live fuels had already died off in a previous cold period and thus responded much faster to the drought event.

These meteorological conditions led to a massive drying of fuels: moisture contents $<15 \%$ dry-weight basis in surface fuels (dead grass and forest litter) were measured by the authors during the dry period. Under this prevailing high fire danger, several fires occurred in higher elevation Alpine forests in Germany and Austria; one of these (the Sylvenstein Reservoir fire) caused great concern, as it burned for several days, was extremely difficult to put out, and with 15 ha accounted for almost half $(47 \%)$ of the annual area burnt in the state of Bavaria (Germany) in 2011. Days with fire occurrences in the relevant area were 9, 11, 20, 21, 25 November (one fire), and 1 December (two fires).

Although this severe fire danger situation (by local standards) was very unusual, it shows features of mountain meteorology (temperature inversion with thermal belt formation and foehn winds) which occur regularly in most areas with complex topography around the world. We examined the behaviour of six selected fire danger indices (Angstrom, Fosberg Fire Weather Index (FFWI), McArthur's Forest Fire Danger Index (FFDI), Fire Weather Index (FWI), Duff Moisture Code (DMC) and Fine Fuel Moisture Code (FFMC), as well as hourly versions of McArthur's FFDI and FFMC) during this period, focusing on the differences between the actual and calculated fire danger in the valleys and at higher elevations and their implications for fire danger rating and management.

\section{Methods}

\subsection{Study site}

In order to calculate fire danger indices for different elevations, a location within the northern Alps was selected where two fully equipped meteorological stations with a marked difference in elevation exist in close proximity and further temperature and humidity data at vertical gradients are available. Garmisch-Partenkirchen, Germany, is located in a wide basin surrounded by the Ammer Mountains (elevations up to 2340 m a.s.1.) to the northwest, the Ester Mountains (elevations up to $2086 \mathrm{~m}$ a.s.l.) to the east and the Wetterstein Mountains (including the Zugspitze, at $2962 \mathrm{~m}$ a.s.l. the highest mountain in Germany) to the south. The flat basin is used mostly for human settlements, infrastructure and agriculture, whereas the lower mountain slopes are covered by forests (approx. 800-1600 m a.s.l., depending on slope, exposition and human use). These forests are usually mixed forests dominated by Norway spruce (Picea abies (L.) Karst.), Euro- pean silver fir (Abies alba Mill.), European beech (Fagus sylvatica $\mathrm{L}$.) and sycamore (Acer pseudoplatanus $\mathrm{L}$.), although pure stands, especially of Norway spruce, can also occur. On south-facing slopes, a significant amount of Scots pine (Pinus sylvestris $\mathrm{L}$.) stands can be found. Higher elevations are covered by grass, dwarf trees and shrubs (mainly mugo pine (Pinus mugo T.)) or bare rock.

\subsection{Meteorological measurements}

The meteorological station "Garmisch-Partenkirchen" is located on the valley floor $\left(719 \mathrm{~m}\right.$ a.s.l., $\left.47.48^{\circ} \mathrm{N}, 11.06^{\circ} \mathrm{E}\right)$. It is run by the German Meteorological Service (Deutscher Wetterdienst, DWD) and supplies hourly values of temperature and relative humidity as well as hourly means of wind speed and hourly precipitation sums.

A second meteorological station, "Felsenkanzel" $\left(1260 \mathrm{~m}\right.$ a.s.1., $\quad 47.51^{\circ} \mathrm{N}, \quad 11.07^{\circ} \mathrm{E}, \quad 2.4 \mathrm{~km}$ horizontal distance from Garmisch-Partenkirchen station), is operated by Technische Universität München. This station is located on a steep south-facing slope near the upper end of the altitudinal forest range and measures selected standard meteorological parameters (temperature, relative humidity, precipitation, and others) at $10 \mathrm{~min}$ intervals. The location of both stations as well as the local topography and areas covered by forest and human settlements are shown in Fig. 2.

Along the south-facing slope, 11 temperature and relative humidity data loggers (HOBO Pro v2 (U23-001) by Onset Computer Corporation) at an altitudinal spacing of $100 \mathrm{~m}$ (700 to $1700 \mathrm{~m}$ a.s.1.) were also operated by Technische Universität München. These HOBO loggers inside a radiation shield at $2 \mathrm{~m}$ above the ground were placed within the existing vegetation (e.g. mixed mountainous forest, Mugo pine shrubbery) at the respective locations. The recording interval was set to $30 \mathrm{~min}$.

In addition, atmospheric sounding data for the whole period were obtained from the nearby radiosonde station at Innsbruck airport $\left(47.26^{\circ} \mathrm{N}, 11.35^{\circ} \mathrm{E}\right.$, approx. $30 \mathrm{~km}$ from Garmisch-Partenkirchen). The standard observation time was 03:00 UTC.

\subsection{Data processing and fire danger index calculation}

All available data for both stations were obtained for 2011 . The $10 \mathrm{~min}$ data of Felsenkanzel were subsequently converted to hourly values and missing parameters (wind speed) were filled by respective data from Garmisch-Partenkirchen, since it was the closest meteorological station available. Some data gaps still remained, but these were short enough not to have any noticeable influence on index calculations.

A wide range of fire danger indices were calculated, representing systems from several continents (North America, Europe, and Australia). All selected indices are based on standard meteorological observations only, since snow parameters and phenology, which are required for some specific 


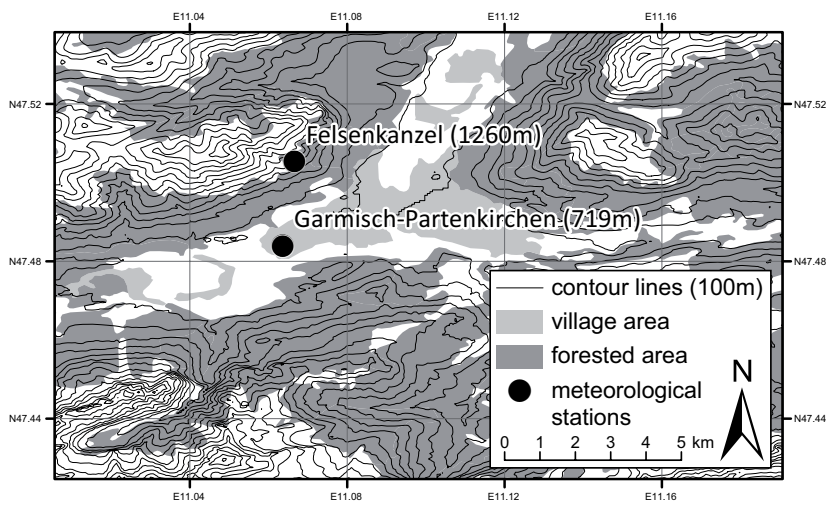

Fig. 2. Elevation, forested area, human settlements and locations of the meteorological stations in the study area.

indices, were not measured at Felsenkanzel. In order to identify even small variations in the index behaviour, all analyses are based on the direct index outputs, without any classification into a danger scale. The indices can be classified into two main groups by their method of calculation: instantaneous and cumulative (e.g. via a bookkeeping system).

The first group is represented by the Angstrom index and the Fosberg Fire Weather Index. Both of these are calculated from meteorological measurements at one point in time only and thus react instantaneously to changes in meteorological conditions.

The Angstrom index is usually calculated for 13:00 local standard time (Chandler et al., 1983; Langholz and Schmidtmayer, 1993) using Eq. (1), where RH is relative humidity in percent and $T$ is temperature in ${ }^{\circ} \mathrm{C}$.

$A=\frac{\mathrm{RH}}{20}+\frac{27-T}{10}$

Although called a fire danger rating system by Chandler et al. (1983), the Angstrom index was actually used as a measure of potential ignition in its place of origin (Chandler et al., 1983). Its values are high in times of low danger/flammability and low in times of high danger/flammability. In addition to the daily values derived from meteorological measurements at 13:00 LST, hourly Angstrom values were additionally calculated from the respective data.

Fosberg's Fire Weather Index (FFWI) is another instantaneous index; however, it is supposed to correlate linearly with fire behaviour. The calculations are based on Byram's (1959) flame length model and Rothermel's (1972) spread model and are given in Eq. (2) (Goodrick, 2002), where $m$ is the equilibrium moisture content calculated from temperature and relative humidity according to Simard (1968) and $U$ is the wind speed in miles per hour.

$\mathrm{FFWI}=\left[1-2 \cdot \frac{m}{30}+1.5 \cdot\left(\frac{m}{30}\right)^{2}-0.5 \cdot\left(\frac{m}{30}\right)^{3}\right] \cdot \sqrt{1+U^{2}}$
The FFWI is typically calculated on an hourly basis. Maximum FFWI was used as a daily FFWI value.

Cumulative indices do not take only the current but also recent weather conditions into account. Therefore, they do not react instantaneously to changes in meteorological variables but show a certain lag (time lag), which may be different for each index.

McArthur's Forest Fire Danger Index (FFDI, Mark 5, Noble et al., 1980) is used in Australia for fire danger, potential rate of spread and difficulty of suppression considerations. Despite this fact, it is said to react quite intensely to the meteorological input variables, especially to wind speed (Boer et al., 2008). It is calculated using Eq. (3), where $T$ is temperature in ${ }^{\circ} \mathrm{C}, \mathrm{RH}$ is relative humidity in percent, $V$ is average wind speed in kilometres per hour, and $D$ is the dimensionless drought factor.

$$
\begin{aligned}
& \text { FFDI }=2.0 \cdot \exp (-0.450+0.987 \cdot \ln (D)-0.0345 \\
& \quad \cdot \mathrm{RH}+0.0338 \cdot T+0.0234 \cdot V)
\end{aligned}
$$

The drought factor itself can be determined from the KeetchByram Drought Index ( $I$, Keetch and Byram, 1968) in mm, the time since rain $(N)$ in days and the amount of precipitation $(P)$ in $\mathrm{mm}$ by applying Eq. (4).

$D=\frac{0.191 \cdot(I+104) \cdot(N+1)^{1.5}}{3.52 \cdot(N+1)^{1.5}+P-1}$

In addition to this daily method, hourly calculations were performed following the procedure described in Boer et al. (2008).

The Fire Weather Index (FWI), the Duff Moisture Code (DMC) and the Fine Fuel Moisture Code (FFMC) are all components of the Canadian Forest Fire Danger Rating System (CFFDRS). The CFFDRS is a semi-empirical system using bookkeeping methods and a relatively large number of equations for its calculation, which are based on 12:00 LST meteorological observations. The exact set of equations and further descriptions can be found in Van Wagner (1987) and Van Wagner and Pickett (1985).

The main index FWI itself combines many effects and is a measure for fire behaviour (Van Wagner, 1987). It depends on temperature, relative humidity, precipitation and wind speed via all other components of the CFFDRS. The other two indices are selected moisture indices for fine fuels (pine litter with a fuel load of $\left.0.25 \mathrm{~kg} \mathrm{~m}^{-2}\right)$ and duff $(7 \mathrm{~cm}$ depth and $5 \mathrm{~kg} \mathrm{~m}^{-2}$ fuel load), respectively. As they represent two distinctly different types of fuels, the indices respond differently to changes in meteorological variables. While the FFMC depends on temperature, relative humidity, and precipitation and reacts rather quickly (time lag of 0.67 days for drying), the DMC increases much slower (time lag of 12 days) and does not require wind speed input data (Van Wagner, 1987). Starting values for 1 January were defined as 85 for FFMC and 6 for DMC, according to Van Wagner and Pickett (1985).

Hourly values of FFMC can generally be calculated using the methods of Lawson et al. (1996) and Van Wagner (1977). 
There has been some discussion regarding the relative performance of those methods (Anderson, 2009; Beck and Armitage, 2001); however, we preferred Van Wagner's (1977) method since it calculates hourly FFMC directly from hourly inputs. Unfortunately, there is no distinct method available to calculate hourly versions of any of the other CFFDRS components; thus, an adaptation of the large set of bookkeeping equations to hourly input is not readily possible.

\subsection{Data analysis}

The meteorological data and the fire danger indices described above were plotted for several time periods. Qualitative comparisons between the particular index progressions were made from visual inspections of these plots.

Independent fire danger assessments were available in the form of expert observations and fire occurrence data. Gravimetric measurements of dead fine fuel (forest litter, dead grass) moisture content were made by the authors on 8 November in the vicinity of the meteorological stations and again on 23 November 2011 (three days after the Sylvenstein Reservoir fire mentioned above), also including a steep slope close to the fire location. Although they support the statements made in this paper, unfortunately all of these additional observations and measurements were sparse and are therefore not adequate for further statistical analysis.

Data from the 11 temperature and relative humidity data loggers and the atmospheric soundings were interpolated in both space and time using a local polynomial regression ("loess") and are shown as contour plots. The atmospheric sounding data for one selected day are displayed as a standard Skew-T Log-P diagram, additionally.

All calculations and plotting were performed with R, version 2.15.0, its packages RadioSonde, version 1.3, and Lattice, version 0.20-6, as well as ArcMAP, version 9.3.

\section{Results}

\subsection{Meteorological conditions during the study period}

Detailed meteorological conditions at both climate stations and from the temperature/humidity logger gradient as well as atmospheric soundings during the period of interest are plotted in Figs. 3 and 4, respectively. No precipitation was recorded at either station in the period 27 October 2011 to 3 December 2011. During this period, temperatures ranged between $-6.6^{\circ} \mathrm{C}$ and $19.5^{\circ} \mathrm{C}$ and relative humidity between 19 and $100 \%$ (extreme values from both stations). However, distinct differences were observed between the two stations. On the valley floor, Garmisch-Partenkirchen experienced more pronounced daily cycles of temperature and humidity, and the mean daily minimum temperature in the period was well below freezing $\left(-1.5^{\circ} \mathrm{C}\right)$. Daily maximum relative humidity was frequently close to $100 \%$ (cf. Fig. 3). In contrast, the Felsenkanzel station at $1260 \mathrm{~m}$ a.s.l. measured

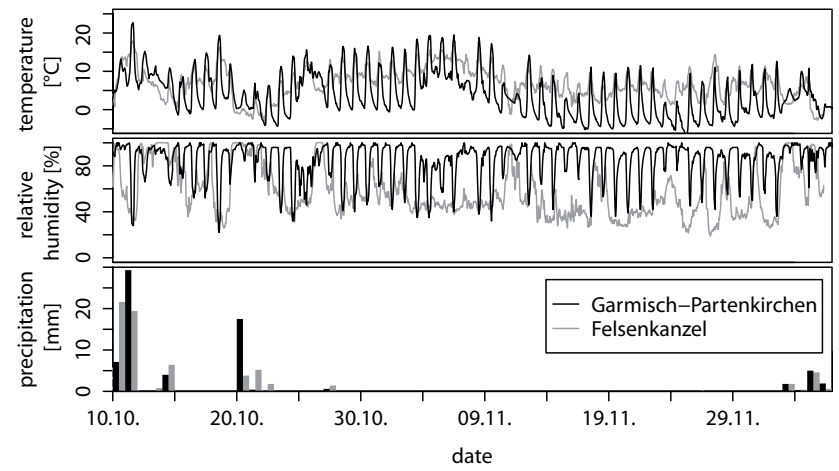

Fig. 3. Meteorological conditions (diurnal course of temperature, relative humidity and daily sum of precipitation) during the exceptional dry period in autumn 2011 at Garmisch-Partenkirchen (black lines/bars) and Felsenkanzel (grey lines/bars) stations. For fire occurrence information, refer to Sect. 1.4.
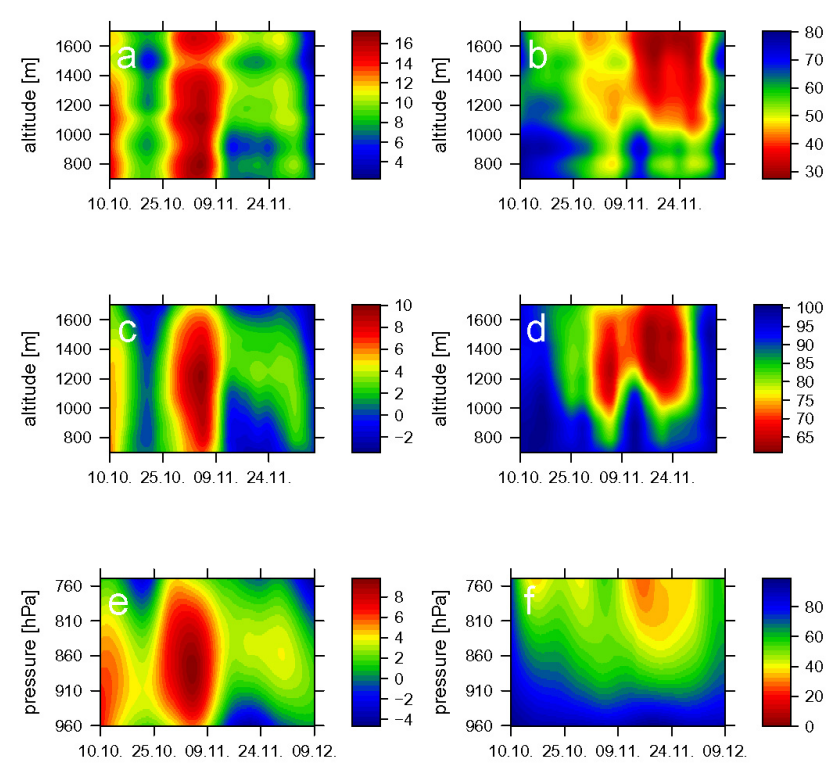

Fig. 4. Meteorological conditions (a daily maximum temperature, $\mathbf{b}$ daily minimum relative humidity, $\mathbf{c}$ daily minimum temperature, $\mathbf{d}$ daily maximum relative humidity) at the south-facing slope where Felsenkanzel station is located. Data from within-stand temperature and relative humidity data loggers. (e) and (f) temperature and relative humidity measured by the daily atmospheric soundings at Innsbruck airport.

less extreme daily cycles with a mean daily minimum temperature of $4.9^{\circ} \mathrm{C}$ and a mean daily maximum humidity of $67.2 \%$.

Figure 4 illustrates the situation along the altitudinal gradient by vertical profiles for maximum and minimum temperature and relative humidity as well as the atmospheric sounding data. Whereas daily maximum temperature and minimum relative humidity from the data loggers display only a modest variation with altitude (Fig. 4a and b), daily minimum 
temperature and maximum relative humidity (Fig. 4c and d) show a clear vertical differentiation linked to the observed nocturnal cool and wet conditions near the valley floor. Additionally, minimum temperatures are shown to be largest at mid-slope elevations, indicating that a thermal belt in the range of 1150 to $1550 \mathrm{~m}$ a.s.l. was present. Maximum relative humidity also reveals a corresponding, though less distinctive, vertical pattern. The Felsenkanzel station located at $1260 \mathrm{~m}$ a.s.1. was almost exactly in the centre of the thermal belt, where the most severe fuel drying conditions existed. Thus, the fuel moisture and fire danger conditions at Garmisch-Partenkirchen and Felsenkanzel can be expected to represent the extremes of what existed during the drought period.

While the temperature and relative humidity data loggers were on-site, it could be argued that their placement within the existing vegetation affected the measurements. For reference, the data of the 03:00 LST atmospheric soundings from Innsbruck are added in Fig. 4e and $\mathrm{f}$ and confirm the thermal belt in the free atmosphere.

Further information on the vertical profiles of temperature, dew point, wind speed and direction for one selected sounding from Innsbruck are shown in a Skew-T Log-P diagram (Fig. 5). The temperature inversion near the ground is clearly visible at a height of up to $1600 \mathrm{~m}(840 \mathrm{hPa})$. Close to the ground, temperature and dew point were identical since the air was saturated and fog occurred. Above, in the thermal belt, temperature was higher and then decreased with altitude. With increasing altitude, the temperature-dew point spread (temperature - dew point) increased until reaching a maximum of $41 \mathrm{~K}$ at $\approx 4500 \mathrm{~m}(580 \mathrm{hPa})$. In this layer, very dry air was present due to strong synoptical subsidence in the high pressure system. While at lower elevations almost no wind was measured, southwesterly to southerly winds of 21-39 knots were measured in higher elevations (above $4500 \mathrm{~m} / 580 \mathrm{hPa}$ ).

This meteorological situation can be considered as a typical example of a stable boundary layer with nightly temperature inversion and thermal belt formation in complex terrain as it frequently occurs in most mountainous areas. Its relevance for forest fire danger will be considered later in this paper (Sects. 3.2 and 3.3). Southerly foehn winds had only minimal effects in this area and period, since a large amount of cold air was present in the valley and the high, west-eastoriented Wetterstein mountain range acted as a barrier for these southerly winds.

\subsection{Annual progression of selected fire danger indices}

The annual progression of the six selected fire danger indices for 2011 is shown in Fig. 6. In addition to the autumn event, a major drought period occurred in spring (end of April beginning of May 2011) and another minor one in summer (end of August 2011).

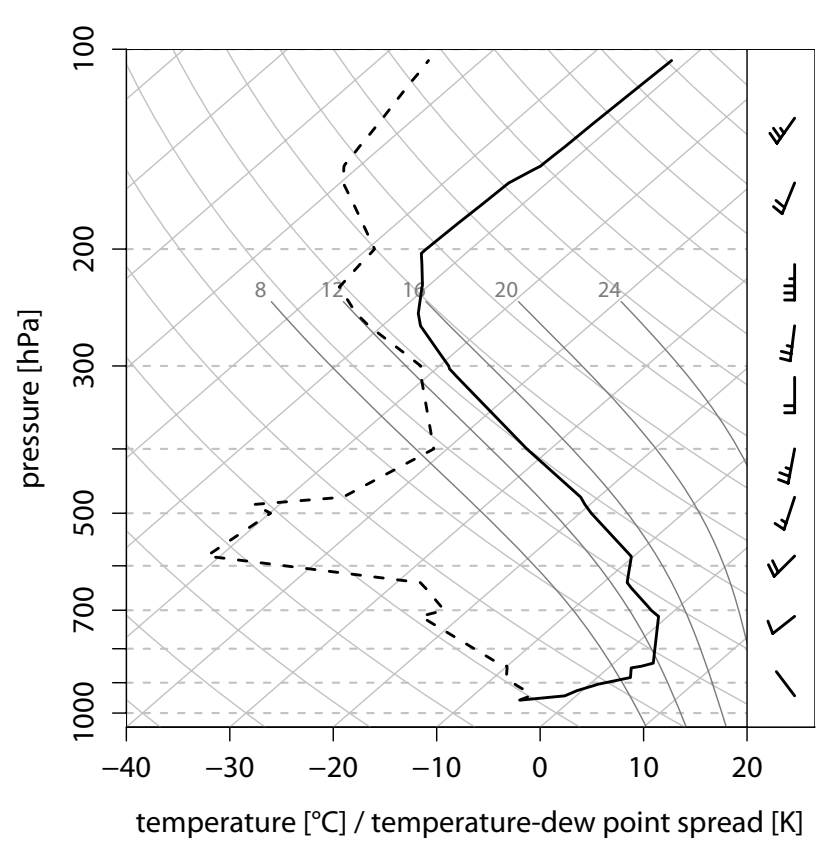

Fig. 5. Skew-T Log-P diagram of the atmospheric sounding taken at Innsbruck airport on 19 November 2011, 03:00 UTC. Solid line: temperature, dashed line: dew point temperature, wind barbs and wind arrows: wind speed and direction, respectively.

Low values of the Angstrom index represent high and high values low potential ignitability. Because of this, the Angstrom index values are plotted inversely in Fig. 6 to match the scaling of the other indices. Due to the high day-today variation in this non-cumulative index, the high danger periods described above do not show up very clearly in the index values of this graph. However, a local decrease of the Angstrom values during these periods and a rise of the index afterwards are detectable.

Fosberg's Fire Weather Index incorporates different meteorological parameters in order to evaluate fire danger and therefore reacts somewhat differently. Nevertheless, the drought periods are indicated clearly by an absence of low maximum FFWI values. However, elevated FFWI values are also found between these events, possibly due to wind speed affecting the potential rate of spread.

The Australian McArthur Forest Fire Danger Index also tends to react quickly, especially when dry conditions are combined with high wind speeds, and reveals the first and second dry periods rather clearly. While the summer event accounts for the maximum McArthur value, only a very moderate rise in the index could be observed in November. The overall values of McArthur's FFDI, however, are very low when compared to those occurring in its place of origin (Dowdy et al., 2009).

The CFFDRS's Fire Weather Index (FWI, another true fire danger index) also mirrors these events quite clearly. Highest values (20 to 25 ) are reached for the spring and summer 


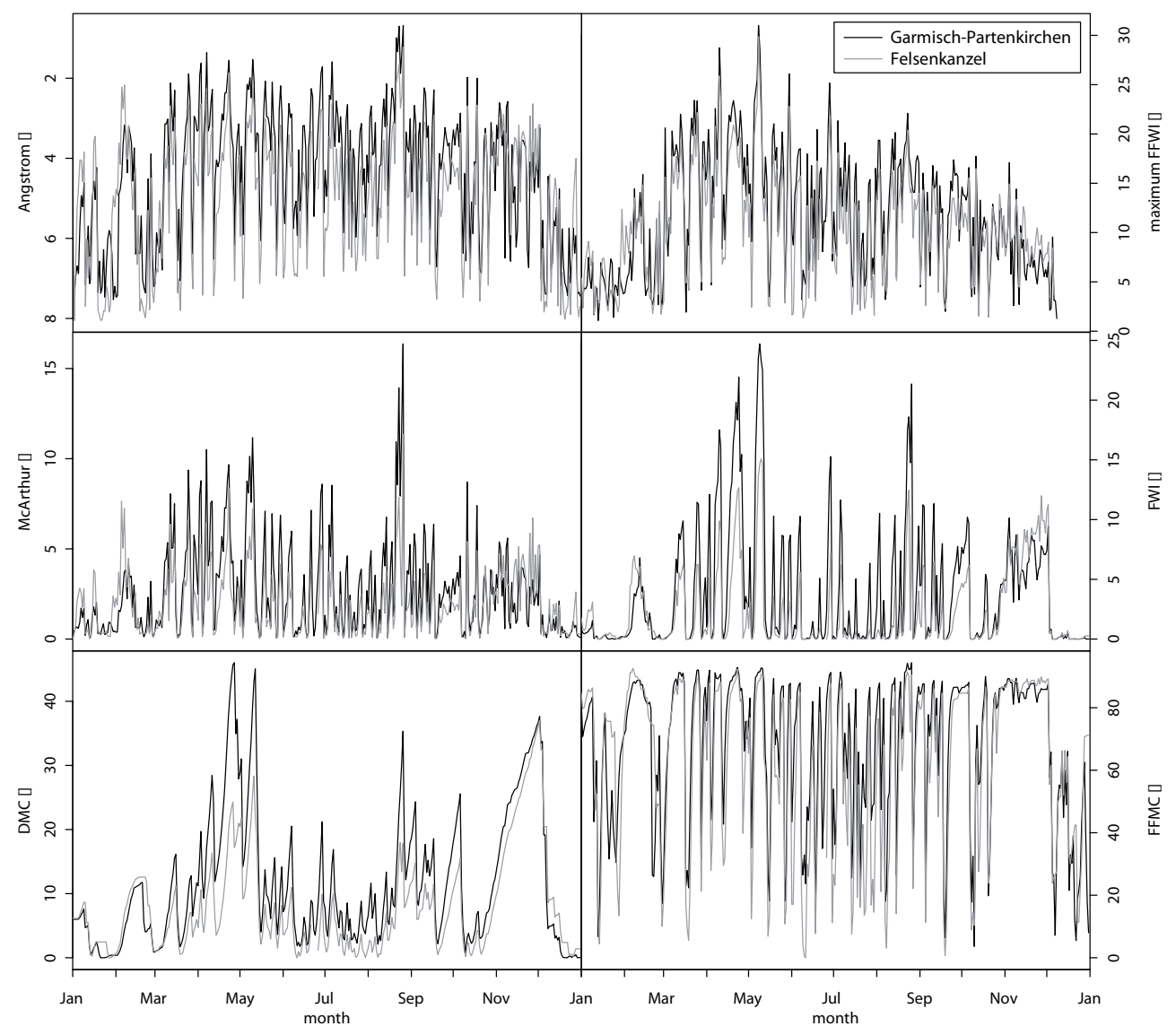

Fig. 6. Selected fire danger indices at Garmisch-Partenkirchen (black line) and Felsenkanzel (grey line) stations in 2011. Note that for the Angstrom index, the $y$ axis has been inverted since high values represent low fire danger and low values represent high fire danger, in contrast to all other indices. For fire occurrence information, refer to Sect. 1.4.

events, whereas the prolonged autumn drought only achieves an FWI of 12.

The Duff Moisture Code (DMC) is a moisture index which responds rather slowly to drought and shows the three events rather clearly. Because of its slower response, it suggests that in autumn the emulated dryness was rising until the end of the drought event. The maximum DMC was obtained for the spring event (maximum value of 46), closely followed by the autumn (maximum value of 38) and summer drought (maximum value of 35) and another short September drought event (maximum value of 26).

The Fine Fuel Moisture Code (FFMC) is yet another moisture index of the CFFDRS, but it reacts much faster, so that it gets close to its maximum value (100) after few days without precipitation. During all danger periods, high or even nearmaximum values of the FFMC could be observed. As the end of the scale was (almost) reached, there was no clear differentiation of the relative severity of the respective danger periods.

When comparing the indices calculated for the two different climate stations (black and grey lines in Fig. 6), it can be noted that fire danger at Felsenkanzel was almost always equal or even lower than Garmisch-Partenkirchen. This is true even for major, usually the first, parts of the autumn drought period, when the actual fire danger, as described above, was much more severe at higher (e.g. Felsenkanzel) than at lower (e.g. Garmisch-Partenkirchen) elevations.

Supporting evidence for this exceptional pattern of fire danger in autumn 2011 is also found in expert-based assessments (e.g. in DWD, 2011a; Raspe et al., 2012; Zimmermann and Raspe, 2012) and information from local forest officers. It is further confirmed by multiple fire occurrences at these elevations in Germany and Austria and the fuel moisture measurements carried out by the authors. The latter showed distinctly lower values (and thus greater fire danger) at midand higher elevations (gravimetric moisture content for dead grass and forest litter between 10 and $25 \%$ ) than near the valley bottom (litter moisture content $>40 \%$ ). Furthermore, the altitudinal variation in fire danger is nicely visualised in Fig. 7, showing rime-covered vegetation in a valley while fire-fighting activities were taking place near the ridge top. 


\subsection{Diurnal meteorological conditions and their impact on fire danger and fire danger rating system calculations}

In order to more closely investigate this striking fact, meteorological conditions and selected fire danger indices have been plotted for part of the autumn drought period (19 to 30 November 2011) in Fig. 8 for which daily and higher resolved calculation of the respective index was possible (cf. Sect. 2.3).

During this period it was quite obvious that the daily amplitudes of both temperature and relative humidity were generally much more pronounced in Garmisch-Partenkirchen (black lines) than at Felsenkanzel (grey lines). In fact, temperature was mostly very low and humidity generally very high at Garmisch-Partenkirchen; only for a short period after noon every day, the temperatures in the valley exceeded those measured at Felsenkanzel and the relative humidity was equal. The reason for this was the disintegration of the nocturnal temperature inversion and thermal belt by strong solar heating during the day in the prevailing high pressure systems. During the night the clear sky caused strong radiative cooling and a gathering of the coldest air on the valley floor (i.e. at Garmisch-Partenkirchen in our case). Hence, the meteorological differences between Garmisch-Partenkirchen and Felsenkanzel were more pronounced during the night. The strong daily cycle for Garmisch-Partenkirchen can be clearly observed at the beginning of the plotted period (19 to 22 November 2011), during which the previously mentioned Sylvenstein Reservoir forest fire started (20 November 2011). Later on, with decreasing day length, the nocturnal temperature inversion and associated fog disintegrated less evenly, leading to less regular cycles of temperature and relative humidity (e.g. 24 November 2011).

Throughout the selected period, both the instantaneous and the cumulative indices as well as those covering fire danger and those covering fuel moisture/potential ignitability showed a response to the drought. The daily index versions (dashed lines in Fig. 8) of all four indices (Angstrom, FFWI, McArthur, and FFMC) rated fire danger as almost identical in the beginning. From 23 November 2011 onwards, conditions were found to be more severe at Felsenkanzel than at Garmisch-Partenkirchen, with the instantaneous indices and McArthur's FFDI showing a distinctly faster reaction to changing environmental conditions than FFMC.

All hourly versions managed to capture the situation much better and showed marked differences between GarmischPartenkirchen and Felsenkanzel from 19 November 2011 onwards. Even a diurnal variation was apparent for GarmischPartenkirchen in all indices, however of a different magnitude depending on the time lag of each individual index. The instantaneous indices but also McArthur's FFDI responded very quickly, whereas the built-in $0.67 \mathrm{~d}$ time lag of the FFMC led to much smoother curves even in the hourly version of this index.

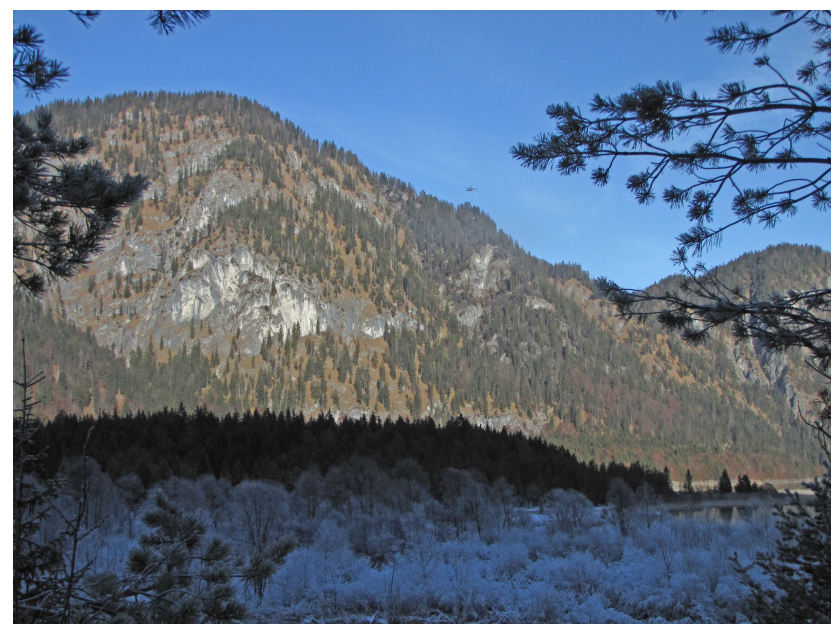

Fig. 7. Mop-up operations are in progress after the Sylvenstein Reservoir fire (near the ridge at the centre of the image) on 23 November 2011, at noon, while rime covers the vegetation in the valley (foreground).

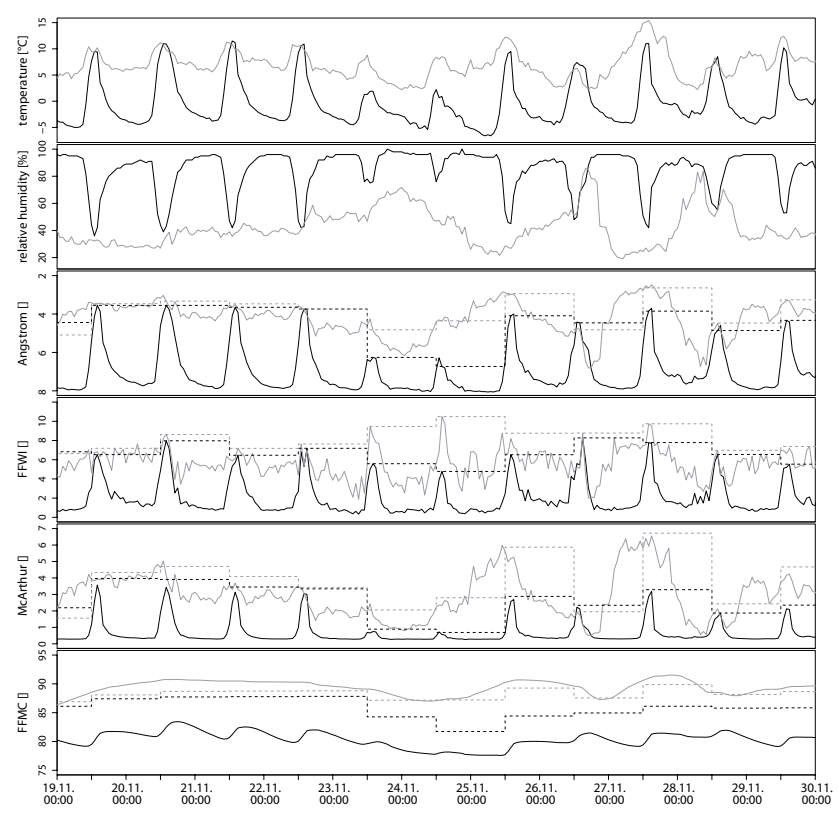

Fig. 8. Meteorological conditions and selected fire danger indices (solid lines: hourly values, dashed lines: daily values) at GarmischPartenkirchen (black lines) and Felsenkanzel (grey lines) stations. Note that for the Angstrom index, the $y$ axis has been inverted since high values represent low fire danger and low values represent high fire danger, in contrast to all other indices. For fire occurrence information, refer to Sect. 1.4.

\section{Discussion}

Daily fire danger rating systems and fuel moisture indices generally seem to misjudge the altitudinal differences in fire danger when a temperature inversion and thermal belt is present, as observed in the selected example of the autumn 
2011 situation (especially in the period 19 to 22 November 2011).

The reason for this lies in the missing sensitivity of most daily fire danger rating systems to the diurnal cycle of meteorological conditions. Except for the FFWI, all daily fire danger indices considered in this study, as well as most known fire danger rating systems, are calculated from meteorological values between 12:00 and 14:00 LST. During this period, as can be gathered from Fig. 8 for our example, meteorological conditions in a valley and a mid-slope position may be almost identical because the temperature inversion (partially) disintegrates during the day due to solar heating (cf. also Fig. 8 in Holden and Jolly, 2011). Therefore the indices use similar input parameters for both locations/stations and are bound to rate fire danger at similar levels. In our example, they neither include the low temperatures and very high humidity at Garmisch-Partenkirchen (so that dew and even rime may occur and wet the fuels) at night nor the almost constant higher temperatures and lower relative humidity (which are likely to cause substantial fuel drying) at Felsenkanzel. Therefore and because temperature inversions are a regular feature in most complex topographic areas, we state that not only can fire danger calculations from lowland stations be expected to be misleading (Sharples, 2009), but even such calculations based on higher elevation stations may provide spurious results if they are carried out only with standard daily fire danger indices. Calculating the FFWI for all hours of the day and then using the daily maximum FFWI practically leads to the same phenomenon, since the maximum FFWI usually occurs in the early afternoon, when meteorological conditions cause highest danger levels.

The assessment based on the hourly indices is quite different and shows a distinctly higher danger at Felsenkanzel and a diurnal variation of the danger level in GarmischPartenkirchen. Therefore this type of index seems much closer to the observed reality. However, the situation at Garmisch-Partenkirchen should probably be rated even less severe, since fuel wetting by dew/rime occurred and there is no such wetting function implemented in any of the indices.

Another fire danger rating system that might be able to correctly account for the phenomenon described here is the National Fire-Danger Rating System (NFDRS, USA, Bradshaw et al., 1983), which uses maximum and minimum temperature and relative humidity in some of its components. Furthermore, there are physically based fuel moisture models available (e.g. Wittich, 2005; Matthews et al., 2007), which can also operate with hourly or higher resolved meteorological data. A new fire danger index, Waldbrandgefahrenindex (WBI, DWD, 2011b), is currently in development at the German Meteorological Service, which will also be able to provide this capability.

\section{Conclusions}

From the fuel measurements, expert observations and fire occurrences during our case study, we can confirm the findings of Holden and Jolly (2011) and Sharples (2009), who stated that temperature inversions may produce unusual and highly heterogeneous patterns of fire danger in mountainous areas. Such a situation may occur at any given time in most complex topographic areas around the world.

Due to the availability of meteorological data from a midslope and a valley station, as well as additional data from a network of temperature and relative humidity data loggers and atmospheric soundings, we managed to analyse how it is resolved by fire danger rating indices. In order to capture the relevant atmospheric conditions, meteorological stations in the valleys and at higher elevations (where forests or other vegetation still occur and a potential thermal belt could develop) or high-resolution meteorological model data are necessary. Note that contrary to most conventional weather stations, which are usually found in the valleys, the "RAWS" stations used for NFDRS calculations in the US are typically located at mid-elevation south-facing slopes (Cohen and Deeming, 1985; Holden and Jolly, 2011). Fire danger rating indices to be used in such areas and situations should be able to correctly account for variations in the daily cycle between the individual stations or grid points. Potential indices are components of the National Fire-Danger Rating System (Bradshaw et al., 1983), hourly calculated Angstrom and FFWI indices, the hourly versions of the McArthur Forest Fire Danger Index (Noble et al., 1980), and the hourly Fine Fuel Moisture Code (Van Wagner, 1977). Further investigation as to which of these or other additional indices are best suited for fire danger rating purposes under the conditions described in this paper are necessary, as our current assessment is limited to qualitative comparisons.

Acknowledgements. The authors would like to acknowledge financial support from the Bavarian State Ministry for Food, Agriculture and Forestry through project KLIP 8 and from the European Union through the Alpine Space ALP FFIRS (no. 15-2-3-IT) project as well as from the European Research Council under the European Union's Seventh Framework Programme (FP7/2007-2013)/ERC grant agreement no. 282250. In this paper, meteorological measurements supplied by the German Meteorological Service (Deutscher Wetterdienst, DWD), the KLIMAGRAD project (funded by the Bavarian State Ministry for the Environment and Public Health) and NOAA's Integrated Global Radiosonde Archive (IRGA, http://www.ncdc.noaa.gov/oa/climate/igra/) have been used. A digital terrain model has been provided by the Bavarian State Office for Surveying and Geographic Information, and Corine Landcover data (CLC2006) by the Federal Office for the Environment, DLR-DFD 2009 has been used in Fig. 2. The authors furthermore gratefully acknowledge the support by the Faculty Graduate Center Weihenstephan of TUM Graduate School at Technische Universität München, Germany. 
Edited by: R. Lasaponara

Reviewed by: three anonymous referees

\section{References}

Anderson, K. R.: A comparison of hourly fine fuel moisture code calculations within Canada, in: Eigth Symposium on Fire and Forest Meteorology, Kalispell, MT, 13-15 October 2009, American Meteorological Society, Boston, 3A.4-3A.10, 2009.

Baumgartner, A., Klemmer, L., and Waldmann, G.: Waldbrände in Bayern 1950 bis 1959, in: Mitteilungen aus der Staatsforstverwaltung Bayerns, Bayerisches Staatsministerium für Ernährung, Landwirtschaft und Forsten, Ministerialforstabteilung, 36, 5779, 1967 (in German).

Beck, J. A. and Armitage, O. B.: Diurnal fine fuel moisture and FFMC characteristics at northern latitudes, in: Proceedings of the 22nd Tall Timbers Fire Ecology Conference: Fire in Temperate, Boreal, and Montane Ecosystems, Tallahassee, FL, 211-221, 2001.

Boer, M. M., Sadler, R. J., Bradstock, R. A., Gill, A. M., and Grierson, P. F.: Spatial scale invariance of southern Australian forest fires mirrors the scaling behaviour of fire-driving weather events, Landscape Ecol., 23, 899-913, doi:10.1007/s10980-008-9260-5, 2008.

Bradshaw, L. S., Deeming, J. E., Burgan, R. E., and Cohen, J. D.: The 1978 National Fire-Danger Rating System: technical documentation, USDA Forest Service General Technical Report INT169, Ogden, Utah, 1983.

Butler, B. W., Bartlette, R. A., Bradshaw, L. S., Cohen, J. D., Andrews, P. L., Putnam, T., and Mangan, R. J.: Fire behavior associated with the 1994 South Canyon Fire on Storm King Mountain, Colorado, USDA Forest Service, Research Paper RMRS-RP-9, Ogden, Utah, 1998.

Byram, G. M.: Combustion of forest fuels, in: Forest fire control and use, edited by: Davis, K. P., 61-89, McGraw Hill, New York, 1959.

Camia, A., Barbosa, P., Amatulli, G., and San-Miguel-Ayanz, J.: Fire danger rating in the European Forest Fire Information System (EFFIS): current developments, Forest. Ecol. Manag., 234, 20 pp., doi:10.1016/j.foreco.2006.08.036, 2006.

Chandler, C., Cheney, P., Thomas, P., Trabaud, L., and Williams, D.: Fire in forestry - forest fire behaviour and effects, John Wiley $\&$ Sons, New York, Chinchester, Brisbane, Toronto, Singapore, 1983.

Cohen, J. D. and Deeming, J. E.: The National Fire Danger Rating System: Basic Equations, USDA Forest Service General Technical Report PSW-82, Berkeley, California, 1985.

Davis, K. P.: Forest fire: control and use, McGraw-Hill Book Company, Inc., New York, Toronto, London, 1959.

Dowdy, A. J., Mills, G. A., Finkele, K., and de Groot, W.: Australian fire weather as represented by the McArthur Forest Fire Danger Index and the Canadian Forest Fire Weather Index, The Centre for Australian Weather and Climate Research, CAWCR Technical Report No. 10, Melbourne, Australia, 2009.

DWD: Deutschlandwetter im November 2011, German Meteorological Service (DWD), press release dated 30 November 2011, Offenbach, Germany, 2011a (in German).

DWD: Informationen zum Waldbrandgefahrenindex WBI, German Meteorological Service (DWD), Offenbach, Ger- many, available at: http://www.dwd.de/bvbw/generator/ DWDWWW/Content/Landwirtschaft/Warndienste/Waldbrand/ wbx__Informationen, templateId=raw, property=publicationFile. pdf/wbx_Informationen.pdf (last access: 15 April 2013), 2011b (in German).

Goodrick, S. L.: Modification of the Fosberg fire weather index to include drought, Int. J. Wildland Fire, 11, 205-211, doi:10.1071/WF02005, 2002.

Gorski, C. J. and Farnsworth, A.: Fire weather and smoke management, in: Mountain meteorology fundamentals and applications, Oxford University Press, New York, 2000.

Holden, Z. A. and Jolly, W. M.: Modeling topographic influences on fuel moisture and fire danger in complex terrain to improve wildland fire management decision support, For. Ecol. Manage., 262, 2133-2141, doi:10.1016/j.foreco.2011.08.002, 2011.

Keetch, J. J. and Byram, G. M.: A drought index for forest fire control, USDA Forest Service Research Paper SE-38, Asheville, North Carolina, 1968.

Langholz, H. and Schmidtmayer, E.: Meteorologische Verfahren zur Abschätzung des Waldbrandrisikos, Allg. Forst Z., 48, 394 396, 1993.

Lawson, B. D., Armitage, O. B., and Hoskins, W. D.: Diurnal variation in the Fine Fuel Moisture Code: tables and computer source code, Canadian Forest Service, B.C. Ministry of Forests, FRDA Report 245, Victoria, BC, 1996.

Matthews, S., McCaw, W. L., Neal, J. E., and Smith, R. G.: Testing a process-based fine fuel moisture model in two forest types, Can. J. For. Res., 37, 23-35, doi:10.1139/x06-207, 2007.

McRae, R. H. D. and Sharples, J. J.: Modelling the thermal belt in an Australian bushfire context, in: MODSIM2011, 19th International Congress on Modelling and Simulation, edited by: Chan, F., and Marinova, D., Anderssen, R. S., Modelling and Simulation Society of Australia and New Zealand, 1652-1658. ISBN: 978-0-9872143-7, December 2011.

Millán, M. M., Estrala, M. J., and Badenas, C.: Meteorological processes relevant to forest fire dynamics on the Spanish Mediterranean coast, J. Appl. Meteorol. 37, 83-100, doi:10.1175/15200450(1998)037<0083:MPRTFF>2.0.CO;2, 1998.

Miller, N. L. and Schlegel, N. J.: Climate change-projected fire weather sensivity: California Santa Ana wind occurrence, Geophys. Res. Lett., 33, L15711, doi:10.1029/2006GL025808, 2006.

Noble, I. R., Bary, G. A. V., and Gill, A. M.: McArthur's firedanger meters expressed as equations, Aust. J. Ecol., 5, 201-203, doi:10.1111/j.1442-9993.1980.tb01243.x, 1980.

Pyne, S. K., Andrews, P. L., and Laven, R. D.: Introduction to wildland fire, 2nd edition, John Wiley \& Sons, New York, Chinchester, Brisbane, Toronto, Singapore, 1996.

Raspe, S., Grimmeisen, W., and Zimmermann, L.: Lange Transpirationsphase der Bäume und Niederschläge ohne Regen, LWF aktuell, 86, 32-33, 2012 (in German).

Rothermel, R. C.: A mathematical model for predicting fire spread in wildland fuels, USDA Forest Service, Research Paper INT115, Ogden, Utah, 1972.

Ryan, B. C.: A vertical perspective of Santa Ana winds in a canyon, USDA Forest Service, Research Paper PSW-52, Berkeley, California, 1969.

Sharples, J. J.: An overview of mountain meteorological effects relevant to fire behaviour and bushfire risk, Int. J. Wildland Fire, 18, 737-754, doi:10.1071/WF08041, 2009. 
Simard, A. J.: The moisture content of forest fuels. I A review of the basic concepts, Forest Fire Research Institute, Information Report FF-X-14, Ottawa, Ontario, 44 pp., 1968.

Van Wagner, C. E.: A Method of computing Fine Fuel Moisture Content throughout the diurnal cycle, Canadian Forest Service, Information Report PS-X-69, Chalk River, Ontario, 1977.

Van Wagner, C. E.: Development and structure of the Canadian forest fire weather index System. Canadian Forestry Service Forestry, Technical Report 35, Ottawa, 1987.
Van Wagner, C. E. and Pickett, T. L.: Equations and FORTRAN Program for the Canadian Forest Fire Weather Index System, Canadian Forestry Service, Forestry Technical Report 33, Ottawa, 1985.

Wittich, K.-P.: A single-layer litter-moisture model for estimating forest-fire danger, Meteorol. Z., 14, 157-164, doi:10.1127/09412948/2005/0017, 2005.

Zimmermann, L. and Raspe, S.: WKS-Witterungsreport: Trockener Herbst und milder Winteranfang, LWF aktuell, 87, 36-37, 2012 (in German). 